\title{
JOURNAL.RU
}

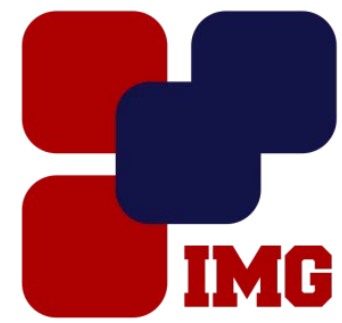

IVanoy
Management
GRoup

Старчакова И.В., Миронова Е.И. Забайкальский государственный университет, МАОУ СОШ с. Улеть Чита, Россия

doi: 10.18411/lj-28-02-2017-4-07

idsp 000001:lj-28-02-2017-4-07

\section{Инновационные технологии в обучении географии}

\section{Аннотация}

Статья посвящена проблеме использования инновационных технологий в обучении географии в современной школе. Представлены теоретические и методические аспекты ряда образовательных технологий: информационных, проектной, игровой, технологии исследовательской деятельности. В статье использованы элементы практического опыта учителя географии.

Ключевые слова: инновационные технологии, технологии обучения, информационно - коммуникативная технология, метод проектов, технология исследовательской и игровой деятельности обучающихся.

Система современного образования требует решения различных задач и проблем, в первую очередь, это проблемы социализации и адаптации обучающихся. Какими будут наши выпускники, зависит в целом от организации образовательного процесса.

В настоящее время определен результат обучения ребенка в школе, согласно Федеральному государственному образовательному стандарту, это формирование ключевых компетенций. Формировать их средствами только традиционной методики невозможно и нецелесообразно. На помощь учителю приходят инновационные образовательные технологии, интерактивные методы и приемы обучения, современные средства обучения, в том числе - мультимедийные учебные материалы. Поэтому современная школа должна быть оснащена компьютерами, проекторами, интерактивными досками, то есть информационными ресурсами.

Реализация современного технологического подхода в обучении географии - это вызов времени. Ведь вклад предмета в формирование системы ценностей личности определяется рядом позиций. Современная географическая наука знакомит школьников с основными методами исследования географической науки (анализ, синтез, прогноз, наблюдение, эксперимент). Это нашло отражение в требованиях к уровню подготовки выпускников в Федеральном государственном образовательном стандарте. Владение методами вооружает обучающихся соответствующими познавательными и практическими умениями (наблюдать, 
создавать образ территории, воспринимать окружающий ландшафт и т.п.); формирует систему прочных и действенных знаний обучающихся, обеспечивает развитие умений самостоятельно работать с различными источниками географической информации, ориентироваться, вести наблюдения в природе и на производстве.

Она также способствует формированию геокомпетентностей, осуществляя тесную связь теории с практикой, с жизнью. Это вносит вклад в профессиональное самоопределение школьников, помогает им выбирать жизненный путь; развивает личностную установку школьников на организацию процесса познания, самостоятельную творческую деятельность.

Исходя из этого, главная задача современного учителя географии формировать у обучающихся готовность использовать усвоенные знания, умения и способы деятельности в реальной жизни для решения практических задач и жизненно значимых ситуаций. Решение данной задачи связано с требованиями, сформулированными в стандарте географического образования. Приобретение компетенций, в свою очередь, базируется на формируемом опыте деятельности обучающихся.

Решение данной задачи невозможно без совершенствования методики обучения географии, в том числе, без использования элементов образовательных технологий. Применяя педагогические технологии на уроках, убеждаемся, что процесс обучения географии можно рассматривать с новой, технологической, точки зрения, добиваясь более качественных результатов.

В практической деятельности учителей географии наиболее часто используются элементы следующих технологий обучения: информационных, проектной, игровой, технологии исследовательской деятельности.

Информационные технологии, т.е. обучение работе с разными источниками информации, как результат - формирование готовности к самообразованию. Эти технологии используются в течение всего периода изучения географии. Учащиеся должны научиться искать информацию, обобщать, систематизировать и делать выводы.

Работая по учебно - методическому комплексу издательства «Русское слово» под редакцией Е.М. Домогацких, можно найти очень много интересных тем для работы с разными источниками информации. Сами учащиеся нередко задаются вопросами исследовательского характера. Например, «Как смог Тур Хейердал повторить плавание людей каменного века в современное время?», «А викинги на самом деле были убийцами, грубиянами, разбойниками или нет?» и т.д. То есть у учащихся вызывают интерес те исторические факты, которые не рассматриваются подробно на уроках, поэтому есть возможность предложить учащимся найти интересующую их информацию и подготовить к уроку сообщение. В этом видится связь с исследовательским методом.

В современной школе существуют разнообразные активные формы обучения: игры, дискуссии, метод мозгового штурма. Развитию активной учебной деятельности обучающихся способствует также педагогическая технология проектной деятельности.

Технология проектной деятельности - педагогическая технология, которая ориентирует не на интеграцию фактических знаний, а на их применение и приобретение новых знаний, в том числе путём самообразования, для активного освоения новых способов человеческой деятельности. 
При этом деятельность учителя и деятельность обучающихся представлена в определенной последовательности, образуя, так называемый проектный цикл. Формируется план деятельности, его выполнение предполагает достижение ожидаемых результатов, которые можно проектировать, педагогическая деятельность - это сплав науки и творчества.

Опыт учителей географии показывает, что при использовании метода проектов, изучение материала идет более успешно. Учебная деятельность, в том числе самостоятельная познавательная, увлекает, если перед обучаемыми ставятся конкретные и практически значимые задачи, к решению которых привлекаются и выше упомянутые информационные технологии.

Сильной мотивационной основой для обучающихся является работа над проектами по интересной и актуальной проблеме, разработка проекта с прикладной и межпредметной направленностью. С учетом специфики предмета географии, ее интегративной сущности, формулировка подобных тем не является очень сложной. Например, в 5-м классе возможно реализация проектов по темам «Как люди открывали мир», «Исследование отдельных материков и их частей», «Русские имена на карте мира», «Действующие вулканы Солнечной системы», «Древнейшие картографические изображения» и другие; в 6 классе «Картографические погрешности на современных картах», «Влияние природных условий на черты народа», «Анализ описания школьной геологической коллекции», «Создание школьной метеорологической площадки» и другие; в 7 классе - «Загадки жизни и личности Христофора Колумба», «Современные исследования Антарктиды», «Из истории географических «закрытий» и другие; в 8-9 классах - «Научное значение путешествий русских землепроходцев в 16-17 вв.», «Метеослужба в России. От основания до наших дней», «Россия в международном разделении труда» и другие; в 10-11 классах - «Оффшорные зоны как результат мировой глобализации», «География международного туризма», «Влияние мирового экономического кризиса 2008-2009 гг. на российскую экономику» и другие.

Особый интерес у выпускников вызвали такие проекты, как: «Визитные карточки стран и регионов мира», «Многоэтажность Японии», «Этот пестрый мир Азии», «Глобальные проблемы человечества», потому что региональный раздел экономической и социальной географии мира вызывает особый интерес. Ребят привлекает многообразие и пестрота картины мира, поэтому они с удовольствием собирают материал о различных регионах и странах, создают свои «визитные карточки», рекламные проспекты.

Проектная деятельность предполагает использование разнообразных форм, методов и средств обучения. Обучающиеся готовят различные доклады, создают презентации о путешественниках, открытиях материков, решают исследовательские задачи, работают в группах, индивидуально.

Реализация проектного метода на уроках требует напряженной работы, нацеливает на применение элементов нелинейных технологий в обучении, на индивидуальную работу с отдельными учащимися, так как участники проекта играют различные роли, оперируют различной информацией, имеют дело с различными объектами, осваивают различные наборы операций. Работа над проектом завершается ролевой игрой.

Качество проекта определяет группа независимых экспертов. Именно они оценивают раскрытие содержания заявленной темы; умение заинтересовать; 
качество слайдов; оформление наглядных материалов; оригинальность и т.д.

С проектной технологией связана технология исследовательского обучения.

Технологии исследовательского обучения (обучение основам исследовательской деятельности). Исследовательская деятельность - такая форма организации работы, которая связана с решением учащимися исследовательской задачи с неизвестным заранее решением.

К элементам исследовательской деятельности относятся методы исследования, экспериментальный материал, интерпретация данных и вытекающие из них выводы. Учителям стоит понимать отличия учебноисследовательской деятельности от научно-исследовательской.

Научно-исследовательская деятельность - это вид деятельности, направленный на получение новых объективных научных знаний.

Учебно-исследовательская деятельность - это деятельность, главной целью которой является образовательный результат, направлена на обучение учащихся, развитие у них исследовательского типа мышления. Главное - не овладение новыми фактами, а научение алгоритму ведения исследования, навыкам, которые могут быть использованы в научном исследовании. Учебное исследование сохраняет логику научного, но не открывает объективно новых для человечества знаний.

В процессе деятельности обучающиеся приобщаются к организации и проведению теоретических и эмпирических исследований, у них происходит формирование целого ряда общекультурных и профессиональных компетенций, развивается научное мышление и познавательная активность. Исследовательская деятельность выступает как условие становления личности, ее способностей, мировоззрения, так как развивает самостоятельность в овладении способами деятельности, в нашем случае, методами исследования.

Элементы исследовательской деятельности формируются в 6-8 классах в процессе подготовки сообщений, проектов. К старшим классам обучающиеся владеют необходимыми умениями и навыками, поэтому они с успехом демонстрируют результаты исследований по теме «Транспорт России: проблемы и перспективы развития», «Изучение загруженности автомобильных дорог в районе Улётовской СОШ».

Учащиеся самостоятельно определяют цель работы: оценить степень загруженности автомобильных дорог в районе Улётовской СОШ в разное время (утро, обеденное время, вечер) и ход работы.

В данном исследовании учитель выступает только координатором, советчиком, так как учащиеся 9-х классов достаточно большие и сами являются руководителями своей же работы.

Учитель в таких работах ставит задачи, которые обязательно выполняются: актуализировать личностный интерес учащихся к изучению темы; помочь осознать социальную, практическую и личностную значимость учебного материала; создать условия для развития умений сравнивать, анализировать; содействовать развитию умений использовать методы познания: наблюдение, эксперимент; обеспечить развитие умений ставить цель и планировать свою деятельность, осуществлять самоконтроль и самооценку.

Наряду с перечисленными технологиями, в практике современного урока географии широко используются элементы игрового обучения.

Технология игровой деятельности. В настоящее время нет единого 
представления о игровом обучении. Игра рассматривается как: прием обучения, направленный на моделирование реальной действительности; прием обучения, направленный на мотивацию учебной деятельности; форма активного обучения; форма организации учебной деятельности; технология обучения. Но, несмотря на это, все-таки определены общие черты обучающих (дидактических) игр. К ним относится - творческий характер деятельности; свобода деятельности ради получения удовольствия, эмоциональная приподнятость, наличие определенных правил, отражающих содержание игры.

Для того, чтобы в процессе игры раскрывался и усовершенствовался творческий потенциал личности, учителя географии используют разнообразные творческие задания. При проведении игр возможна уровневая дифференциация обучающихся, а, следовательно, и реальный контроль базового уровня знаний на основе образовательных стандартов.

При работе в команде школьники учатся определять проблемы, обсуждать их, искать пути решения, в этой ситуации формируется коллективное мышление. Работа в команде создает чувство защищенности у слабых учеников, они уверены, что товарищи их поддержат, помогут с ответом.

Такие уроки способствуют развитию речи школьников, учат их доказывать свою точку зрения, аргументировать ответ.

Ребят привлекает нетрадиционная форма урока, необычное оформление кабинета, работа с дополнительными источниками знаний.

Чаще всего, игры проводятся на уроках повторения, закрепления, систематизации и обобщения знаний.

Модульная технология. Учитывая, что модульная технология - это сочетание целей, принципов, способов проектирования, конструирования дидактических материалов, рейтинговая система оценки и контроля достижений, полагаем, что технология предполагает создание модуля - особого функционального узла, в котором учитель объединяет содержание учебного материала и технологию овладения им учащимися.

Считаем необходимым показать преимущества модульной технологии: генерализация учебного материала, его разбивка на блоки-модули; комплексное планирование цели и задач урока; оптимальная последовательность этапов; дифференцированный подход к учащимся; усиление мотивации обучения; самооценка и саморегуляция учащимися своих учебных достижений; варьирование функции педагога от информационно-контролирующей до консультационно-координирующей; адаптация к индивидуальным особенностям обучаемых за счет диагностики знаний и темпа усвоения; гарантия запланированных конкретных результатов в обучении учащихся; варьирование компонентов модуля согласно образовательным задачам.

Наиболее полно модульная технология используется в старших классах, где у учащихся сформированы общегеографические знания, общеучебные, универсальные и специальные умения, развивается абстрактное мышление и географический кругозор. Поэтому проектируются более разнообразные элементы данной технологии.

В качестве примера реализации элементов модульной технологии в 10 классе предлагаем таблицу. 
Тематический план модуля «Современная политическая карта мира»

\begin{tabular}{|c|c|c|c|c|c|}
\hline Тема & $\begin{array}{c}\text { Форма } \\
\text { занятия }\end{array}$ & $\begin{array}{c}\text { Форма } \\
\text { контроля }\end{array}$ & $\begin{array}{c}\text { Связь } \\
\text { элементов } \\
\text { модуля }\end{array}$ & Знания & Умения \\
\hline $\begin{array}{c}\text { Совреме } \\
\text { нная } \\
\text { политиче } \\
\text { ская } \\
\text { карта } \\
\text { мира }\end{array}$ & Лекция & $\begin{array}{c}\text { Выборочная } \\
\text { или } \\
\text { обязательная } \\
\text { проверка } \\
\text { лекционных } \\
\text { записей }\end{array}$ & - & $\begin{array}{c}\text { Современная } \\
\text { политическая } \\
\text { карта мира, } \\
\text { качественные и } \\
\text { количественные } \\
\text { изменения, } \\
\text { типология, } \\
\text { многообразие } \\
\text { стран, форма } \\
\text { правления, форма } \\
\text { устройства, } \\
\text { политические } \\
\text { организации }\end{array}$ & $\begin{array}{c}\text { Слушать лекцию, } \\
\text { составлять конспект, } \\
\text { вести краткие записи } \\
\text { в виде структурных } \\
\text { схем и } \\
\text { систематических } \\
\text { таблиц, используя } \\
\text { сокращения и } \\
\text { символы. }\end{array}$ \\
\hline $\begin{array}{c}\text { Совреме } \\
\text { нная } \\
\text { политиче } \\
\text { ская } \\
\text { карта } \\
\text { мира }\end{array}$ & Практикум & $\begin{array}{c}\text { Обязательная } \\
\text { проверка } \\
\text { выполнения } \\
\text { задания в } \\
\text { тетради и на } \\
\text { контурной } \\
\text { карте }\end{array}$ & $\begin{array}{c}\text { Выполняется } \\
\text { на основе } \\
\text { теоретическог } \\
\text { о материала } \\
\text { лекции и } \\
\text { самостоятель } \\
\text { ной работы с } \\
\text { учебным } \\
\text { пособием, } \\
\text { атласом, } \\
\text { дополнительн } \\
\text { ой } \\
\text { литературой } \\
\end{array}$ & $\begin{array}{c}\text { Повторение } \\
\text { понятий, } \\
\text { полученных на } \\
\text { лекции }\end{array}$ & $\begin{array}{c}\text { Развитие умений, } \\
\text { полученных на } \\
\text { лекции. Работа с } \\
\text { различными } \\
\text { источниками } \\
\text { информации: } \\
\text { учебник, карта, } \\
\text { контурная карта и др. }\end{array}$ \\
\hline $\begin{array}{c}\text { Совреме } \\
\text { нная } \\
\text { политиче } \\
\text { ская } \\
\text { карта } \\
\text { мира }\end{array}$ & Диалог & $\begin{array}{c}\text { Анализ и } \\
\text { оценка } \\
\text { выступлений } \\
\text { учащихся. }\end{array}$ & $\begin{array}{c}\text { Выполняется } \\
\text { на основе } \\
\text { теоретическог } \\
\text { о материала } \\
\text { лекции, } \\
\text { практикума и } \\
\text { самостоятель } \\
\text { ной работы с } \\
\text { учебным } \\
\text { пособием, } \\
\text { атласом, } \\
\text { дополнительн } \\
\text { ой } \\
\text { литературой, } \\
\text { материалов } \\
\text { СМИ } \\
\end{array}$ & $\begin{array}{c}\text { Повторение } \\
\text { знаний, } \\
\text { полученных на } \\
\text { лекции и } \\
\text { практикуме }\end{array}$ & $\begin{array}{c}\text { Для подготовки к } \\
\text { уроку необходимо } \\
\text { развитие умений, } \\
\text { полученных на } \\
\text { лекции и пракикуме. } \\
\text { Работа с различными } \\
\text { источниками } \\
\text { информации: } \\
\text { учебник, карта, } \\
\text { контурная карта и } \\
\text { др., развитие } \\
\text { диалогической речи, } \\
\text { коммуникативных } \\
\text { способностей } \\
\text { учащихся. } \\
\end{array}$ \\
\hline $\begin{array}{c}\text { Совреме } \\
\text { нная } \\
\text { политиче } \\
\text { ская } \\
\text { карта } \\
\text { мира }\end{array}$ & $\begin{array}{c}\text { Пресс- } \\
\text { конференц } \\
\text { ия }\end{array}$ & $\begin{array}{c}\text { Анализ и } \\
\text { оценка } \\
\text { выступлений } \\
\text { учащихся, } \\
\text { выступающих } \\
\text { в роли } \\
\text { экспертов, } \\
\text { корреспонден } \\
\text { тов, } \\
\text { политологов } \\
\text { и др. }\end{array}$ & $\begin{array}{c}\text { Выполняется } \\
\text { на основе } \\
\text { теоретическог } \\
\text { о материала } \\
\text { лекции, } \\
\text { практикума, } \\
\text { диалога и } \\
\text { самостоятель } \\
\text { ной работы с } \\
\text { учебным } \\
\text { пособием, } \\
\text { атласом, } \\
\text { дополнительн } \\
\text { ой } \\
\text { литературой, } \\
\text { материалов } \\
\text { СМИ }\end{array}$ & $\begin{array}{c}\text { Повторение } \\
\text { знаний, } \\
\text { полученных на } \\
\text { лекции, } \\
\text { практикуме и } \\
\text { диалоге }\end{array}$ & $\begin{array}{c}\text { Для подготовки к } \\
\text { уроку необходимо } \\
\text { развитие умений, } \\
\text { полученных на } \\
\text { лекции, практикуме и } \\
\text { диалоге. Работа с } \\
\text { различными } \\
\text { источниками } \\
\text { информации: } \\
\text { учебник, карта, } \\
\text { контурная карта и } \\
\text { др., развитие } \\
\text { диалогической и } \\
\text { монологической } \\
\text { речи, } \\
\text { коммуникативных } \\
\text { способностей } \\
\text { учащихся. }\end{array}$ \\
\hline
\end{tabular}




\begin{tabular}{|c|c|c|c|c|c|}
\hline $\begin{array}{c}\text { Совреме } \\
\text { нная } \\
\text { политиче } \\
\text { ская } \\
\text { карта } \\
\text { мира }\end{array}$ & Семинар & $\begin{array}{c}\text { Оценка } \\
\text { ответов, } \\
\text { выступлений }\end{array}$ & $\begin{array}{c}\text { Глубокое } \\
\text { творческое } \\
\text { развитие, } \\
\text { осмысление } \\
\text { изученных } \\
\text { вопросов }\end{array}$ & $\begin{array}{c}\text { Расширение } \\
\text { полученных } \\
\text { теоретических } \\
\text { знаний }\end{array}$ & $\begin{array}{c}\text { Самостоятельно } \\
\text { готовиться к занятию } \\
\text { на основе всех } \\
\text { предыдущих } \\
\text { элементов системы, } \\
\text { участвовать в } \\
\text { обсуждении } \\
\text { поставленных } \\
\text { вопросов, выделять } \\
\text { главное, развитие } \\
\text { монологической } \\
\text { речи, умения } \\
\text { слушать, задавать } \\
\text { вопросы и т.д. }\end{array}$ \\
\hline $\begin{array}{c}\text { Совреме } \\
\text { нная } \\
\text { политиче } \\
\text { ская } \\
\text { карта } \\
\text { мира }\end{array}$ & Зачет & $\begin{array}{c}\text { Оценка } \\
\text { ответов } \\
\text { учащихся, } \\
\text { самооценка }\end{array}$ & $\begin{array}{c}\text { Зачет } \\
\text { строится на } \\
\text { основе } \\
\text { содержания } \\
\text { всех } \\
\text { предыдущих } \\
\text { уроков }\end{array}$ & $\begin{array}{c}\text { Знание понятий, } \\
\text { причинно- } \\
\text { следственных } \\
\text { связей, } \\
\text { закономерностей, } \\
\text { фактов и } \\
\text { представлений. }\end{array}$ & $\begin{array}{c}\text { Умение } \\
\text { устанавливать } \\
\text { причинно- } \\
\text { следственные связи, } \\
\text { логично отвечать на } \\
\text { поставленные } \\
\text { вопросы, } \\
\text { анализировать карты, } \\
\text { материалы СМИ. }\end{array}$ \\
\hline
\end{tabular}

Таким образом, считаем, что урок - это важнейшая организационная форма процесса познания мира обучающихся, их развития и воспитания.

У современного педагога вообще, и у учителя географии в частности, должна быть парадигма мышления и деятельности, ориентированная на современного ученика, у которого проявляется интерес к познанию, способности к самостоятельной познавательной деятельности. Построение урока с использованием элементов разнообразных инновационных образовательных технологий помогает повысить этот интерес.

\section{Литература}

1. Душина И.В., Пятунин В.Б., Таможняя Е.А. Методика и технология обучения географии / И.В. Душина, В.Б. Пятуни, Е.А. Таможняя. - М.: ООО «Изд-во Астрель»: ООО «Изд-во АСТ», 2002.- 203 с.

2. Обухов А.С. Исследовательская деятельность как путь становления субъектности участников образовательного процесса. /Материалы межд. научно-практ. конференции, Москва, МПГУ: В 2-х ч.- Ч.1. - М.: МАНПО, 2010. - 771с.

3. Старчакова И.В. Современные аспекты использования объяснительно-иллюстративных технологий в практике школьного географического образования. // География в школе: научно-педагогический журнал, №1 2012. - С. 54-57 